
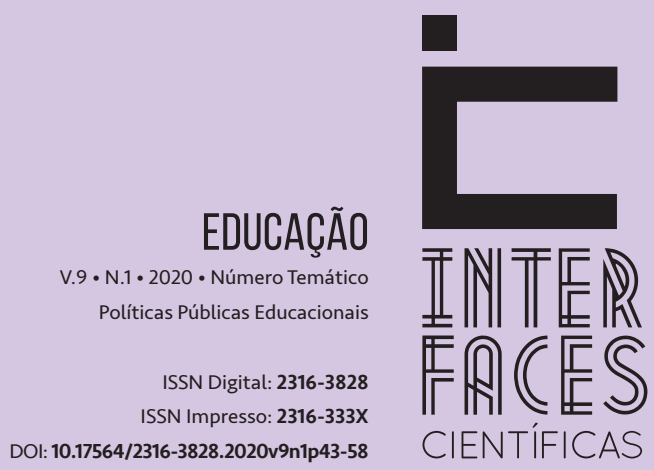

CIENTÍFICAS

\section{AS LEGISLAÇ̃ES E O PÚBLICO INFANTOJUVENIL: HÁ CONEXÃO COM A CONTEMPORANEIDADE?}

LEGISLATIONS AND THE CHILDREN'S PUBLIC: IS THERE A CONNECTION WITH CONTEMPORANEITY?

LEGISLACIONES Y EL PÚBLICO INFANTO-JUVENIL: ¿HAY UNA CONEXIÓN CON LA CONTEMPORANEIDAD?

Ana Maura Martins Castelli Bulzoni

Aparecido Renan Vicente ${ }^{2}$

Andreza Marque de Castro Leão

\section{RESUMO}

0 presente artigo tem por objetivo descrever um panorama histórico-social em relação as legislações às crianças e aos adolescentes no Brasil. Pretende-se estudar, dessa maneira, as principais leis existentes que protegem o público infanto-juvenil. Após buscas nos periódicos e apreciação dos títulos, foram descartados os artigos científicos que discorriam acerca de outros temas que não traziam contribuição direta para este estudo. Desse modo, este artigo de cunho bibliográfico abordou as seguintes áreas: abandono de recém-nascidos, crianças, exploração do trabatho infantil, preconceito, discriminação, violência sexual, entre outros temas acerca das legislações. Concluiu-se que o Estado, a escola e a família são instituições sociais que estão nos dias hodiernos com dificuldades em proteger crianças e adolescentes, o que aponta para a necessidade das legislações serem colocadas em práticas, de maneira que assegurem efetivamente a proteção de crianças e adolescentes, considerando a necessidade premente de serem, de fato, protegidas.

\section{PALAVRAS-CHAVE}

Legislações. Proteção. Criança. Adolescente. 
The present article aims to describe a historical-social panorama regarding the laws of children and adolescents in Brazil. It is intended to study, in this way, the main existing laws that protect the juvenile public. After searching the journals and reviewing the titles, the scientific articles that discouraged about other topics that did not directly contribute to this study were discarded. Thus, this bibliographic article addressed the following areas: abandonment of newborns, children, exploitation of child labor, prejudice, discrimination, sexual violence, among other topics about legislation. It was concluded that the State, the school and the family are social institutions that are nowadays having difficulties to protect children and adolescents, which points to the need for the legislation to be put into practice, so that effectively ensure the protection of children and adolescents, considering the urgent need to be, in fact, protected.

\section{KEYWORDS}

Legislation. Protection. Child. Adolescent

\section{RESUMEN}

El presente artículo tiene como objetivo describir un panorama histórico-social sobre las leyes de niños, niñas y adolescentes en Brasil. Se pretende estudiar, de esta manera, las principales leyes existentes que protegen al público infanto-juvenil. Después de buscar en las revistas y apreciar los títulos, se descartaron los artículos científicos que desaconsejaban otros temas que no contribuyeron directamente a este estudio. Así, este artículo bibliográfico abordó las siguientes áreas: abandono de recién nacidos, niños, explotación del trabajo infantil, prejuicios, discriminación, violencia sexual, entre otros temas sobre legislación. Se concluyó que el Estado, la escuela y la familia son instituciones sociales que actualmente tienen dificultades para proteger a los niños, niñas y adolescentes, lo que indica la necesidad de que la legislación se ponga en práctica, para garantizar efectivamente la protección de los niños y adolescentes, considerando la urgente necesidad de estar, de hecho, protegidos.

\section{PALABRAS CLAVE}

Legislación. Protección. Niño. Adolescente 


\section{INTRODUÇ̧̃̃o}

A condição da criança e do adolescente como sujeitos de direitos é uma realidade recente na história brasileira. Vale lembrar que a história dos direitos da infância, assim como, da criança propriamente dita, é uma construção social. Durante todo o percurso histórico, sobretudo no período da Antiguidade até a idade Média, as crianças e a infância não eram entendidas enquanto sujeitos de direitos, portanto eram vistas como "pessoas" de menor valia na sociedade.

O historiador elucida:

O sentimento da infância não existia - o que não quer dizer que as crianças fossem negligenciadas, abandonadas ou desprezadas. 0 sentimento da infância não significa 0 mesmo que afeição pelas crianças: corresponde à consciência da particularidade infantil, essa particularidade que distingue essencialmente a criança do adulto, mesmo jovem. Essa consciência não existia. (ARIĖS, 1981, p. 156).

Ariès (1981) expressa que às crianças nos séculos XIV, XV e XVI eram vistas como adultos em miniatura, sendo que o tratamento social que recebiam era igual ao dispensado aos adultos. Dada a ausência de consideração de infância neste período histórico, logo, as crianças participavam de todos os assuntos da sociedade e adquiriam o conhecimento por meio do convívio social.

$O$ autor coaduna com Ariès, o pensamento, e pontua:

Adultos, jovens e crianças se misturavam em toda atividade social, ou seja, nos divertimentos, no exercício das profissões e tarefas diárias, no domínio das armas, nas festas, cultos e rituais. 0 cerimonial dessas celebrações não fazia muita questão em distinguir claramente as crianças dos jovens e estes dos adultos. Até porque esses grupos sociais estavam pouco claros em suas diferenciações. (VOLPATO, 2002, p. 16).

Neste contexto histórico, a educação das crianças consistia em serviços domésticos, visto que elas não permaneciam muito tempo em suas famílias, porquanto por volta dos sete anos iam conviver com outras famílias para serem educadas, muitas vezes preparadas para realizarem serviços domésticos ou ainda para aprenderem algum ofício.

No século XVI, iniciou-se uma mudança a qual melhorou a compreensão acerca da concepção de crianças e da infância. Com a colonização do Brasil, os europeus, enquanto colonizadores trouxeram seus valores, costumes e, naturalmente, suas ideias referentes à infância para o Brasil. Assim, dentro dessa nova construção moderna, foram sendo soterradas concepções de criança como um adulto em miniatura e aos poucos essa ideia cedeu lugar para a afirmação da infância como uma construção social.

Del Priore (2004) retrata o sentimento de paparicação na época colonial brasileira elucidando que as

Crianças pequenas, brancas ou negras, passavam de colo em colo e eram mimadas à vontade, tratadas como pequenos brinquedos. (...) As pequenas crianças negras eram considera- 
das graciosas e serviam de distração para as mulheres brancas que viviam reclusas, em uma vida monótona. Eram como que brinquedos, elas as agradavam, riam de suas cambalhotas e brincadeiras, lhes davam doces e biscoitos [...]. (DEL PRIORE, 2004, p. 89-111).

Notadamente era um sentimento distorcido, uma vez que as crianças eram tratadas como objeto lúdico dos adultos. Segundo Ariès (1981), as classes populares europeias continuaram tendo por muito tempo, a ideia de uma infância curta e fundida com os adultos.

Del Priore (2004) expõe que no Brasil colonial, a partir dos sete anos, os filhos de senhores iam estudar, enquanto os pobres e escravos trabalhavam. A educação dos filhos, a partir do século XVIII era entregues às escolas. Os pais, nesse período, queriam poupar um pouco do seu tempo.

Em decorrência da revolução industrial e com o processo de industrialização, a família perdeu uma de suas funções e a escola se estendeu a todas as camadas sociais, com a missão de educar para o trabalho as crianças, impondo sobre elas uma mentalidade de obediência e disciplina.

De acordo com Del Priore (2004, p.45), "[...] já nas primeiras décadas do século XIX, que os dicionários assumiram o uso reservado da palavra 'criança' para a espécie humana”. Em especial, as crianças tornam-se o centro das atenções e passam a constituírem tema e possibilidades de estudos e observações. Desta forma, iniciando pela Europa, a criança vai assumindo identidade, voz e estatuto legal.

\section{MÉTODO}

O presente estudo foi elaborado a partir de uma revisão bibliográfica, sendo que para a sua redação foram extraídos os aspectos mais importantes das produções científicas, dando ênfase no contexto histórico da infância e juventude, bem como aos direitos previstos em lei para este público.

No tocante à pesquisa bibliográfica, segundo autor:

A pesquisa bibliográfica é desenvolvida com base em material já elaborado, constituído principalmente de livros e artigos científicos. Embora em quase todos os estudos seja exigido algum tipo de trabalho dessa natureza, há pesquisas desenvolvidas exclusivamente a parir de fontes bibliográficas. (GIL 2002, p. 44).

Foram considerados os descritores; abandono de recém-nascidos, crianças, exploração do trabalho infantil, preconceito, discriminação e violência sexual. Utilizou-se para a busca as bases de dados Banco de Dados de periódicos da CAPES, Direitos Humanos, Scientific Eletronic LIbray Online (SCIELO) Brasil, Google Acadêmico e 1 capítulo de livro.

Consoante (GIL, 2002, p. 45) “a principal vantagem da pesquisa bibliográfica reside no fato de permitir ao investigador a cobertura de uma gama de fenômenos muito mais ampla do que aquela que poderia pesquisar diretamente". O referido autor ainda expõe que cabe ao pesquisador analisar minuciosamente cada informação, a fim de verificar possíveis incoerências ou contradições e utilizar fontes variadas, e, portanto, cotejando-as cuidadosamente. 


\section{AS LEGISLAÇ̃̃ES NOS SEUS DIREITOS E PROTEÇÃO}

É preciso aprofundar acerca das principais legislações que regem os direitos e deveres das crianças e adolescentes, principalmente as pessoas que trabalham com a educação.

Ao fazer uma retrospectiva histórica, até meados do século XIX não havia legislações que protegiam as crianças e adolescentes. A Constituição da República dos Estados Unidos do Brasil, promulgada em 24 de fevereiro de 1891, não fazia menção quanto às garantias de proteção à criança e ao adolescente.

No início do século XX, mais especificamente em 1927, foi promulgado o primeiro Código de Menores, popularmente conhecido como Código Mello Mattos, que regulava apenas os menores em situação irregular, regulamentando questões como trabalho infantil, abandono em instituições religiosas (antigas “rodas"), tutela, pátrio poder, delinquência e liberdade vigiada, concedendo ainda plenos poderes ao juiz.

Já a Constituição dos Estados Unidos do Brasil promulgada em 16 de julho de 1934, no Título IV, em que se refere à “Da Ordem Econômica e Social”, no art. 1384, pela primeira vez fez alguma referência quanto aos direitos da criança e do adolescente.

No século XX, em 10 de novembro de 1937, durante o governo de Getúlio Vargas, foi então promulgada a Constituição dos Estados Unidos do Brasil, inserindo dispositivos que buscavam o dever do Estado na garantia do direito da criança e do adolescente. Assim, no art. 16, inc. XXVII, o presente documento refere-se à competência de a União legislar sobre as normas concernentes à defesa e proteção da saúde e da criança. No art. 127 do citado documento, a infância e a juventude são objetos de cuidado e de garantias especiais por parte do Estado. Nos artigos art. 129 e 130, apresenta que é dever concorrente da nação, dos estados e dos municípios a garantia de acesso ao ensino público e gratuito.

Por sua vez, a Constituição de 18 de setembro de 1946 instituiu a obrigatoriedade à assistência na maternidade, bem como o legal amparo à família de prole numerosa, conforme disposto no art. 1645 . De acordo com Baptista (2012), em 1948, foram promulgadas a Declaração Universal dos Direitos Humanos e, no referido documento, estavam previstos não somente direitos dos adultos, mas também direitos das crianças e adolescentes, visto que a infância e adolescência também necessitam de cuidados.

Durante a ditadura militar no Brasil, foi promulgada a legislação acerca da criança e do adolescente, prevendo a criação da Fundação Nacional do Bem-Estar do Menor (FUNABEM), Lei 4.513 de 01/12/64. Essa lei tinha como objetivo implantar a política nacional do bem-estar do menor, herdando do SAM (órgão do Ministério da Justiça e que funcionava como um equivalente do sistema

4 Art. 138 - Incumbe à União, aos Estados e aos Municípios, nos termos das leis respectivas: a) assegurar amparo aos desvalidos, criando serviços especializados e animando os serviços sociais, cuja orientação procurará coordenar; b) estimular a educação eugênica; c) amparar a maternidade e a infância; d) socorrer as famílias de prole numerosa; e) proteger a juventude contra toda exploração, bem como contra o abandono físico, moral e intelectual; f) adotar medidas legislativas e administrativas tendentes a restringir a moralidade e a morbidade infantis; e de higiene social, que impeçam a propagação das doenças transmissíveis; g) cuidar da higiene mental e incentivar a luta contra os venenos sociais.

5 Art. 164 - É obrigatória, em todo o território nacional, a assistência à maternidade, à infância e à adolescência. A lei instituirá o amparo de famílias de prole numerosa. 
Penitenciário para a população menor de idade) o prédio e o pessoal e, com isso, toda a sua cultura organizacional. A FUNABEM propunha-se a ser a grande instituição de assistência à infância, cuja linha de ação tinha internação tanto dos abandonados e carentes quanto dos infratores, os quais consistiam no principal foco.

Em 24 de janeiro de 1967, fica instituída a Lei da Constituição da República Federativa do Brasil que determinava a assistência à maternidade, à infância e à adolescência, segundo o que preconiza o art. $167^{6}, \S 4^{\circ}$ no Título IV que trata “Da Família, da Educação e da Cultura”.

Em 17 de outubro de 1969, a Emenda Constitucional no 1, de 17 de outubro de 1969, dispôs em seu art. 175, § $4^{\circ}$ sobre a assistência à maternidade, à infância e à adolescência, além da educação dos excepcionais, a qual seria regida por lei especial. Em 1979, foi promulgado o novo Código de Menores por meio da Lei 6.697 de 10/10/79. Este código foi criado no final do regime militar, apenas ratificando uma visão consolidada e ultrapassada, a qual ignorava garantias às crianças a adolescentes, considerados objetos de direitos, ao invés de sujeitos de direito.

Dezenove anos mais tarde, no dia 5 de outubro de 1988, promulgou-se a Constituição da República Federativa do Brasil. Esta ainda permanece em vigor até os dias de hoje e trouxe maior ênfase quanto à proteção dos direitos à criança e ao adolescente, estendendo a responsabilidade à família, à sociedade e ao Estado, assumindo a proteção integral as crianças e adolescentes, de acordo no caput do art. $227^{7}$ e, na continuidade no $\$ 4^{08}$ do mesmo dispositivo, estabelecendo normas punitivas na forma da Lei sobre o abuso, violência e a exploração sexual da criança e do adolescente. Evidencia-se que a demanda das garantias e proteção à criança e ao adolescente percorreu um período muito longo, até que consideraram um assunto imprescindível perante a lei.

Após a promulgação da Constituição da República Federativa do Brasil de 1988, em 13 de julho de 1990, proclamou-se o Estatuto da Criança e do Adolescente (ECA), instituído por meio da Lei $n^{\circ}$ 8.069, que regulamentou o dispositivo constitucional.

Assim sendo, a Lei 8.069/90 (ECA) consolidou uma conquista da sociedade brasileira, pois trouxe avanços significativos na vida das crianças e adolescentes, corroborando na efetivação dos direitos sociais deles. Nesta legislação, definiu-se as idade de criança e adolescente, portanto é considerada criança a pessoa de até 12 anos de idade e adolescente aquele entre 12 aos 18 anos de idade, regulamentando a proteção integral a infância e a adolescência, visto que crianças e adolescentes passaram a serem respeitados enquanto sujeito de direitos, garantindo-lhes premissas fundamentais de direito à vida e dignidade.

As crianças e adolescentes, em razão disso, deixaram de ser vistos como "menores" ou um problema a ser tratado e, portanto, passaram a ser protagonistas com direitos fundamentais, garantido

6 Art. 167 - A família é constituída pelo casamento e terá direito à proteção dos Poderes Públicos. $§ 4^{\circ}$ - A lei instituirá a assistência à maternidade, à infância e à adolescência.

7 Art. 227. É dever da família, da sociedade e do Estado assegurar à criança, ao adolescente e ao jovem, com absoluta prioridade, o direito à vida, à saúde, à alimentação, à educação, ao lazer, à profissionalização, à cultura, à dignidade, ao respeito, à liberdade e à convivência familiar e comunitária, além de colocá-los a salvo de toda forma de negligência, discriminação, exploração, violência, crueldade e opressão. (Redação dada Pela Emenda Constitucional $n^{0} 65$, de 2010)

$8 \mathrm{Art.} 227, \S^{\circ}$ - A lei punirá severamente o abuso, a violência e a exploração sexual da criança e do adolescente. 
por Lei. Notadamente, o ECA concedeu prioridade à criança e ao adolescente, afirmando-lhes direito à vida, à dignidade, ao respeito, à saúde, à cultura, à educação, à alimentação, ao esporte, ao lazer, à profissionalização, à liberdade e à convivência familiar e social.

Com efeito, o Estatuto da Criança e do Adolescente entrou em vigência no ano de 1990 e, no ano seguinte, 1991, engendrou-se no Brasil o Conselho Nacional dos Direitos da Criança e do Adolescente (CONANDA), órgão cujo objetivo era unir e criar diretivas nacionais, a fim de que os direitos das crianças e dos adolescestes fossem salvaguardados conforme orienta o referido estatuto.

Corroborando ao que expõe o CONANDA a Resolução $n^{0}$ 133, institucionalizou o Sistema de Garantia de Direitos da Criança e do Adolescente (SGD), sendo que diversos segmentos contribuem à garantia dos direitos infantojuvenis, a saber: educação, saúde, trabalho, esporte, lazer, cultura, assistência social e sociedade civil (BAPTISTA, 2012). Portanto, a união de todas áreas formou a intersetoriedade, ou seja, todos atuando em consonância com as legislações.

Cabe lembrar que outrora não havia leis e tampouco resoluções que amparavam a população infanto-juvenil, visto que os bebês eram abandonados nas rodas dos expostos e as crianças que apresentavam comportamentos não aceitáveis para época eram punidas de acordo com o Código de Menores (PERETTI, 2017).

\section{LEGISLAÇÃO E CONTEMPORANEIDADE}

Com o advento das vastas legislações a partir do século XX e com o designo em proteger a criança e ao adolescente e respeitá-los enquanto sujeitos e protagonistas sociais, verificou-se que na contemporaneidade há um longo caminho a ser percorrido quanto à prática na sociedade brasileira.

Nesta perspectiva, adentram novas condutas na sociedade como um todo, ganhando relevância novas práticas sociais, tais como a dos educadores, dos médicos, dos juízes, dos policiais, dos assistentes sociais e cada vez mais fica evidente a necessidade de crescentes intervenções.

Com efeito, muitas crianças e adolescentes nascidas hoje vivenciam práticas do passado, sendo impedidas de vivenciar os direitos que perpassam nas diferentes fases do desenvolvimento enquanto crianças e adolescentes. Aliás, poucas delas têm o privilégio de brincar, estudar e vivenciar os momentos próprios das fases do desenvolvimento peculiares.

O Estatuto da Criança e do Adolescente expressa no

Art. $3^{\circ} \mathrm{A}$ criança e ao adolescente gozam de todos os direitos fundamentais inerentes à pessoa humana, sem prejuízo da proteção integral de que trata esta Lei, assegurando-se Ihes, por lei ou por outros meios, todas as oportunidades e facilidades, a fim de thes facultar o desenvolvimento físico, mental, moral, espiritual e social, em condições de liberdade e de dignidade. (BRASIL, 2017, p. 11).

Frente ao histórico da infância e juventude, observa-se as alterações que aconteceram a fim de propiciar o cuidado e o respeito a esta fase, pois a luta árdua foi colocar nas laudas a lei para proteger crianças e adolescentes. Em dias hodiernos, a luta é se efetivar de fato os direitos já alcançados. 
As crianças na contemporaneidade estão sendo vista pelas instituições sociais de uma forma preocupante, sendo percebidas como crianças agressivas, carentes afetivamente, superestimuladas e que sofrem, muitas vezes, violência dentro de casa.

Há falha no Estado quanto à legislação, instituição família e quanto à prática do respeito aos direitos iguais. Assim, apesar dos avanços das legislações brasileiras, o que se pontua aqui são alguns desafios a serem transpostos para garantir o efetivo atendimento integral às crianças e aos adolescentes, como o direito à educação, à qualidade no ensino, às oportunidades de inclusão social e à extinção da mão de obra infantil.

Acrescenta-se que, atualmente, encontram-se nas ruas crianças e adolescentes, abordando pessoas para vender produtos, ou até, sendo exploradas sexualmente para obter dinheiro de maneira a ajudar a família. Elas vão em depósitos de lixos da cidade em busca de alimentos, sendo comuns crianças abandonadas, caminhando pelos bairros centrais e/ou periféricos, dormindo nas calçadas sobre papelões e jornais em busca de sobrevivência, contrariando o art. $5^{\circ}$ do ECA ${ }^{9}$. Por meio de notícias dos meios de comunicação intui-se a exploração do trabalho infantil em locais como lavoura e outros locais nos quais atividades braçais necessitam de mão de obra barata.

Nesse sentido, "é muito provável que grande contingente de crianças e adolescentes submetidos ao trabalho infantil, permaneça boa parte de sua vida nos estratos mais baixos da população, sempre submetidas a trabalho de níveis inferiores ou ao próprio desemprego" (LIETEN, 2007, p. 27).

A exploração do trabalho infantil existe desde o tempo da colônia. Por exemplo, crianças tinham que prestar serviços nas embarcações, as quais traziam colonizadores. As crianças prestavam serviços que as colocavam em alto risco. Portanto sua plenitude não era considerada e respeitada, além de que recebiam diversos tipos de punição (CUSTÓDIO, 2007, p. 17 apud PAGANINI, 2011, p. 2).

De acordo com Passetti (1999), com o advento da Lei 8.069/1990, o Brasil começaria um processo de mudança. Assim, em 1994, o país iniciaria um viver de novas experiências, isto é, fomentar a prevenção e erradicar com o trabalho infanto-juvenil a partir da criação do Fórum Nacional de Prevenção e Erradicação do Trabalho Infantil. Ainda segundo este autor:

[...] se constatava que no Brasil havia uma importante lacuna: carecíamos de uma instância que tivesse por objetivo a articulação de diferentes setores da sociedade que tinham estratégias, movimentos comuns, evitando, assim, a duplicação de forças, o que poderia inclusive dividir o esforço de erradicar o trabalho infantil. (PASSETTI, 1999, p. 270).

De acordo com os dispositivos do Estatuto da Criança e do Adolescente, é vedado o trabalho que coloque em risco a formação e o desenvolvimento físico, psíquico, moral e social da criança e do adolescente em horários e lugares que interfere na vida estudantil daqueles que não atingiram a maioridade, de acordo com o art. 67 inciso I, III, IV10 (BRASIL, 2017).

9 Art. $5^{\circ}$ Nenhuma criança ou adolescente será objeto de qualquer forma de negligência, discriminação, exploração, violência, crueldade e opressão, punido na forma da lei qualquer atentado, por ação ou omissão, aos seus direitos fundamentais. 10 Art. 67. Ao adolescente empregado, aprendiz, em regime familiar de trabalho, aluno de escola técnica, assistido em entidade governamental ou não-governamental, é vedado trabalho: I - noturno, realizado entre as vinte e duas horas de um dia e 
Assim, o ECA orienta em seu art. $60^{11}$ que é proibido qualquer tipo de trabalho a adolescente de idade inferior de 16 anos, salvo em condição de aprendiz, ainda restringe sua realização em locais prejudiciais à sua formação e ao seu desenvolvimento físico, psíquico, moral e social, bem como àqueles realizados em locais e horários que não permitem que o adolescente esteja na escola (BRASIL, 2017).

No ECA, há ainda a proibição do trabalho penoso, realizado em locais prejudiciais à formação e ao desenvolvimento físico, psíquico, moral e social do adolescente em horários e locais que não permitam a frequência à escola aos adolescentes menores de dezoito anos - art. 67, I, III, IV (BRASIL, 2017).

Apesar de estar nítido o trabalho infanto-juvenil no país, faz-se necessário evidenciar que o Brasil deu salto qualitativo no sentido de formação de políticas públicas no que se refere a prevenção e a erradicação do trabalho infantil, seja com a consolidação de novas políticas públicas, seja com implantação de programas, por meio de Fóruns de Prevenção do Trabalho Infantil (CUSTÓDIO, 2009, p. 56).

Para melhor compreensão serão apresentadas denúncias feitas no Brasil acerca da Exploração do Trabalho Infantil entre 2014 a 2017. Os dados foram extraídos do Dique 100 e apresentado na Tabela 1.

Tabela 1 - Denúncias de exploração do trabalho infantil no Brasil período entre 2014 e 2017

\begin{tabular}{l|c}
\hline Ano & Total \\
\hline 2014 & 5660 \\
\hline 2015 & 4542 \\
\hline 2016 & 4690 \\
\hline 2017 & 5355 \\
\hline
\end{tabular}

Fonte: Disque 100.

Verifica-se na Tabela 1, resultado significativo de denúncias realizadas no Dique 100. Mesmo com a diminuição e aumento de um ano para o outro, o número continua sendo expressivo. Contudo, as pessoas precisam ser mais ainda informadas, a fim de que mais denúncias sejam formalizadas, pois é possível que muitas não façam registro por não terem conhecimento da ilegalidade do trabalho infanto-juvenil.

as cinco horas do dia seguinte; II - perigoso, insalubre ou penoso; III - realizado em locais prejudiciais à sua formação e ao seu desenvolvimento físico, psíquico, moral e social; IV - realizado em horários e locais que não permitam a frequência à escola. 11Art. 60. É proibido qualquer trabalho a menores de quatorze anos de idade, salvo na condição de aprendiz. 
Assim, toda criança e adolescente (meninos e meninas até 15 anos) em situação de trabalho deve ser retirada imediatamente das atividades laborativas, como determina a lei (Emenda Constitucional $n^{\circ} 20,15 / 12 / 1998$, que altera o artigo $7^{\circ}$, inciso XXXIII ${ }^{12}$ da Constituição Federal e a Lei $n^{\circ}$ 8.069/90-Estatuto da Criança e Adolescente).

A denúncia deverá ser registrada nos órgãos competentes, isto é: Ministério Público Estadual; Ministério Público do Trabalho; Conselho Tutelar; Delegacia de Proteção à Criança e ao Adolescente; Juizado da Infância e Juventude, pois todos os cidadãos têm a incumbência de denunciar ao presenciar, ouvir e, ou, até se a criança e/ou adolescente fizer algum tipo de revelação de violação de direito.

Presencia-se, adentrando da ausência da proteção à criança e adolescentes, com frequência relatos nas mídias, em geral, de pedofilia, violência sexual e violência física nas próprias famílias, sendo que a marginalização da infância continua a existir em grande proporção.

Além disso, foram notadas as contradições evidentes entre as leis e a prática no convívio da proteção para com as crianças e adolescentes, visto que com esses fatos evidentes apreendeu-se que há uma morosidade da implementação das políticas públicas para a infância em sua execução, bem como, em sua fiscalização.

A violência sempre se fez presente nas relações entre pessoas, sendo que a falta de políticas públicas tem colaborado substancialmente para o seu crescimento. Portanto, é de conhecimento comum que crianças e adolescentes diariamente sofrem algum tipo de violência física, psicológica, social ou sexual. De acordo com a Organização Mundial (OMS), a concepção de violência tal qual pode-se verificar nesse contexto é definida como sendo o

[...] uso intencional da força física ou do poder, real ou em ameaça, contra si próprio, contra outra pessoa, ou contra um grupo ou uma comunidade, que resulte ou tenha grande possibilidade de resultar em lesão, morte, dano psicológico, deficiência de desenvolvimento ou privação.

Segundo afirma Minayo (2017), a violência se altera e se torna um problema para área da saúde, pois comove a saúde individual e, ou do grupo, sendo que a solução para sanar é fazer prevenção a fim de que novas políticas públicas sejam de fato efetivadas.

Cabe apontar que há quatro tipos de violência reconhecidos: violência física, violência sexual, violência psicológica e negligência (GUERRA, 1998). A violência física está relacionada ao uso de força física no contato com a criança, seja por seus pais e/ou responsáveis ou por alguém que exerça uma função de autoridade no núcleo familiar. Tal relação de força tem a ver com o poder do adulto e a desigualdade adulto-criança, sendo que a criança estará sempre em desvantagem.

A violência sexual acontece quando há o ato ou jogo sexual, seja na relação hetero ou homossexual, entre adultos e crianças, com o objetivo de fomentar sexualmente a criança a fim de obter prazer sexual (AZEVEDO; GERRA, 1998, p. 33).

12 Art. $7^{\circ}$ São direitos dos trabalhadores urbanos e rurais, além de outros que visem à melhoria de sua condição social: XXXIII - proibição de trabalho noturno, perigoso ou insalubre a menores de dezoito e de qualquer trabalho a menores de dezesseis anos, salvo na condição de aprendiz, a partir de quatorze anos. 
Apresenta-se, a seguir, o Gráfico 1, concernente as denúncias que foram registradas junto ao Disque 100, Direitos Humanos.

Gráfico 1 - Denúncias do disque 100

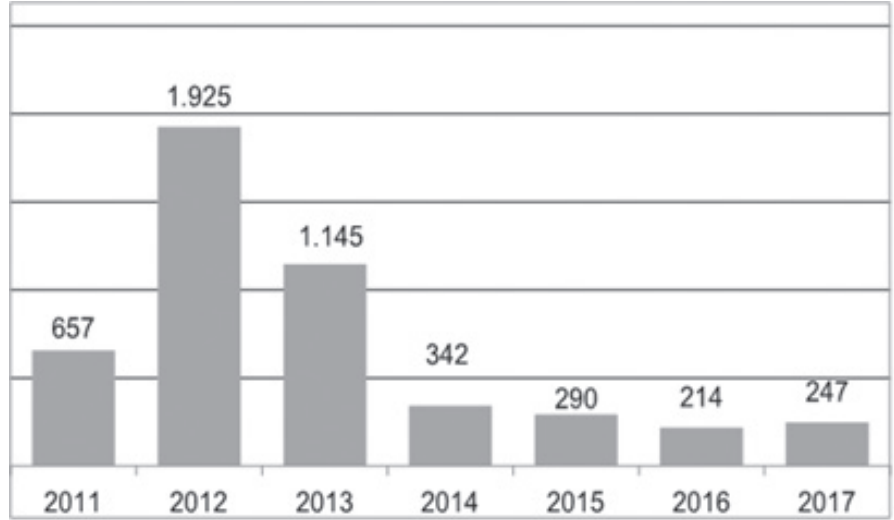

Denúncias de violência sexual realizadas junto ao Direitos Humanos Fonte: Disque 100.

Em relação à violência sexual, observa-se que, no ano de 2012, foram registradas mil novecentos e vinte e cinco denúncias. Já em 2013 foram mil cento e quarenta e cinco denúncias, pouco menos em relação ao ano anterior, todavia, um montante muito significativo. No ano de 2011 , foram registradas seiscentos e cinquenta e sete denúncias e, em 2014, trezentos e quarenta e dois casos de violência sexual.

Em 2015, executaram-se duzentos e noventa denúncias. Embora esse montante de denúncias seja menor em relação aos outros anos, ainda continua sendo alarmante a quantidade de notificações. No que se refere ao ano de 2016, se comparado com o ano de 2017, verifica-se que houve um aumento de denúncias registradas junto ao Disque 100. As denúncias registradas no Direitos Humanos são encaminhadas às cidades de origem da criança ou adolescente, a fim de que as autoridades competentes tomem as devidas providências.

Os estudiosos versam que a violência sexual perpetradas contra crianças e adolescentes geralmente é ininterrupta, portanto, às vezes ela se estende por alguns anos, sendo interrompida com a quebra do silêncio da vítima. Há, também, situações em que a criança presenciou irmãos, primos e, ou, amigos sendo violentados sexualmente e, por isso, apresenta comportamento de medo e temor pelo autor (FILHO, 2002).

A violência psicológica pode acontecer de diversas formas, sendo que é denominada como "tortura psicológica”. 0 adulto interfere de forma negativa na relação com a criança e no seu meio social, estabelecendo um modelo de comportamento destruidor. 0 abuso psicológico não é tão fácil de ser detectado, pois não se faz só presente somente no núcleo familiar, mas, também, em ambientes externos da criança. 
Entende-se por negligência quando a família se omite em fornecer os cuidados inerentes ao desenvolvimento da criança, mais precisamente quando os pais e/ou responsáveis deixam de alimentar, vestir, educar, assim como não favorecendo uma ambiência favorável à criança.

0 abandono não fica isento, pois há muitos pais que estão presentes na vida de seus filhos, porém, estão ausentes na vida emocional e estudantil, atitude esta que vai na contramão do Art. 129, inciso V. ${ }^{13}$

Diante das variadas formas supramencionadas dos tipos de violência, o Estatuto da Criança e do Adolescente aponta em seu artigo 98 que:
As medidas de proteção à criança e ao adolescente são aplicáveis sempre que os direitos reconhecidos nesta Lei forem ameaçados ou violados:
I- Por ação ou omissão da sociedade ou do Estado;
II- Por falta, omissão ou abuso dos pais ou responsável;
III- em razão de sua conduta.

O Brasil foi o primeiro país a formar políticas públicas na área da infância e juventude, e, mesmo assim, os direitos para esta fase da vida continuam sendo violados por omissão da sociedade e/ou Estado, pela falta dos pais e pelo próprio comportamento do adolescente.

Apesar da existência de políticas públicas, ainda há números expressivos de violação de direitos das crianças e adolescentes que, por sinal, servem para mostrar o quão longe à nação se encontra para expressar se houve algum tipo de mudança na realidade infanto-juvenil, levando em consideração o que era outrora, bem como no relacionamento de pais-filhos.

Embora os direitos das crianças e adolescentes estejam expostos na Constituição da República, Estatuto da Criança e do Adolescente, decretos e resoluções, ainda não é suficiente (DORNELAS; COELHO; OLIVEIRA, 2012).

No tocante a políticas de enfrentamento, é importante enaltecer que, em 2004, o Governo Federal promoveu ações as quais culminaram em três programas de dois órgãos federais: Programa de Erradicação do Trabalho Infantil (PETI), Programa Sentinela e o Programa de Enfrentamento da Violência Sexual Infanto-juvenil no Brasil (PAIR).

No ano de 2010, o país contava com treze programas que incluíam onze Ministérios do Governo, o que naquele momento explicitou o comprometimento do país para que os direitos das crianças e dos adolescentes fossem garantidos (DORNELAS; COELHO; OLIVEIRA, 2012).

\section{CONCLUSÃO}

Com base nas leis mencionadas e ao refletir sobre as práticas dos dias atuais, nos introduz conjeturar quanto às políticas para a infância no Brasil. Nesta perspectiva, com tantas implementações de po-

13 Art. 129. São medidas aplicáveis aos pais ou responsável: V- obrigação de matricular o filho ou pupilo e acompanhar sua frequência escolar. 
líticas públicas voltadas para crianças e adolescentes, é possível perceber muitas falhas no sentido de garantir à proteção efetiva a elas, o que faz repensar a questão das concepções da infância atualmente.

É preciso utilizar meios de comunicação, a fim de levar informação do Estatuto da Criança e do Adolescente, pois só assim a população elaborará estratégias de modo a atenuar o trabalho infanto-juvenil. No Brasil, se faz necessária a efetiva participação popular na fiscalização, execução e controle das políticas públicas realizadas pelo estado, para que se possa assim efetivar todos os direitos das crianças e adolescentes.

Na medida em que a população fiscaliza e notifica os órgãos competentes acerca de ameaças ou violações de direitos, serão minimizados o montante de trabalho infantil, de exploração sexual, consequentemente, a população infanto-juvenil terá seus direitos e, sobretudo, sua dignidade preservada.

Apontar a importância de se estabelecer, por meio de políticas educacionais, uma formação de sujeito com direitos, deveres e possibilidades de vir a ser na sociedade um indivíduo formado integralmente nos seus aspectos físicos, emocionais, culturais, psíquico, cognitivo e social.

Outrossim, cabe salientar que é dever não só do Estado, mas sim de todos cidadãos criar meios que promovam o crescimento saudável e digno de crianças e adolescentes, considerando que as políticas públicas estão alocadas nos territórios de forma descentralizada e seu maior objetivo é a universalidade de acesso, integralidade e equidade.

O Estado e a sociedade civil, em geral, não são capazes de assegurar plenamente a proteção à criança e aos adolescentes no Brasil. Estas deficiências no que tange a assegurar de fato segurança e proteção perpassam neste momento atual todas as instâncias e instituições e não tão somente o poder público, embora sua responsabilidade seja evidente.

Além de as políticas públicas não conseguirem minimizar os impactos negativos presentes nas vidas das crianças e adolescentes, também não oferecem para profissionais formações continuadas à fim de estarem aptos no atendimento de excelência.

Assim, o país se mostra repleto de leis eficazes que, porém, precisam ser executadas efetivamente para que seja possível aperfeiçoar o atendimento junto a essas crianças e adolescentes, proporcionando-lhes uma vida digna enquanto seres dotados de direitos.

\section{REFERÊNCIAS}

ARIĖS, P. História social da criança e da família. 2. ed. Rio de Janeiro: Zahar, 1981. p. 279. Trad. Dora Flaksman.

AZEVEDO, M. A.; GUERRA, V. N. A. Pele de asno não é só história: um estudo sobre a vitimização sexual de crianças e adolescentes em família. São Paulo: Rocca, 1998.

BRASIL. Constituição da República Federativa do Brasil de 1988. Disponível em: http://www. planalto.gov.br/ccivil_03/Constituicao/ConstituicaoCompilado.htm. Acesso em: 14 nov. 2019. 
BRASIL. Estatuto da Criança e do Adolescente e dá outras providências. Disponível em: http:// www.planalto.gov.br/ccivil_03/Leis/L8069Compilado.htm Acesso em: mar. 2016.

BAPTISTA, M. V. Algumas reflexões sobre o sistema de garantia de direitos. Serviço Soc., v. 109, p. 179-199, 2012.

DATASUS. Morbidade hospitalar do SUS por causas externas. Disponível em: http://tabnet. datasus.gov.br/cgi/deftohtm.exe?sih/cnv/fiuf.def. Acesso em: ago. 2018.

DORNELAS, A. G.; COELHO, J. M. V.; OLIVEIRA, W. F. Exploração Sexual de Criança e Adolescentes (ESCA): Análise do enfrentamento sob uma perspectiva histórica. ATHENAS, v. I, n. 2, jul.-dez. 2012.

FILHO, F. M. Generalidades sobre a atuação das Varas da Infância e da Juventude. In: MALLAK, L. S.; VASCONCELOS, M. G. O.M. Compreendendo a violência sexual em uma perspectiva multidisciplinar. Carapicuíba-SP: Fundação Orsa Criança e Vida, 2002. p. 37-41.

GIL, A. C. Como elaborar Projeto de Pesquisa. 4. ed. São Paulo, 2002. p. 64.

LIETEN, G. K. 0 problema do trabalho infantil: temas e soluções. Curitiba, PR: Multidéia, 2007.

PAGANINI, J. $O$ trabalho infantil no Brasil: uma história de exploração e sofrimento. Amicus Curiae, v. 5 , n. 5 (2008), 2011. Disponível em: http://periodicos.unesc.net/index. php/amicus/article/ viewFile/520/514. Acesso em: 2 ago. 2018.

PASSETTI, E. Crianças carentes e políticas públicas. In: PRIORE, Mary Del (Org.). História das crianças no Brasil. São Paulo: Contexto, 1999.

PERETTI, A. G. Discursos normativos e de profissionais da rede de proteção à infância: o trabalho intersetorial contra a violência em uma região de São Paulo. 2017. Dissertação (Mestrado) Faculdade de Medicina da Universidade de São Paulo, São Paulo, 2017.

PRIORE, Mary Del (Org.). História das crianças no Brasil. 5. ed. São Paulo: Contexto, 2004

VOLPATO, G. Jogo e brinquedo: reflexão a partir da teoria crítica. V. 3, n. 3. Montes Claros: Unimontes, 2002. 
1 Doutoranda em Educação Escolar pela Faculdade de Ciências e Letras - UNESP. Brasil;

E-mail: mauradil@gmail.com

2 Mestrando em Educação Sexual pela Faculdade de Ciências e Letras - UNESP. E-mail: renanvct.psico@yahoo.com

3 Doutora em Educação Escolar pela Faculdade de Ciências e Letras - UNESP; Professora da FCLAr - UNESP.

E-mail: andreza_leao@yahoo.com.br

\section{口ira \\ Pritring

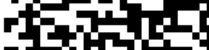

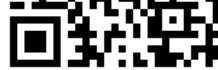

\section{(2) (1) (-)}

Este artigo é licenciado na modalidade acesso abertosob a Atribuição-Compartilha Igual CC BY-SA

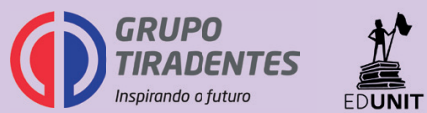


